\title{
Corrigendum
}

\section{Longitudinal effects of acculturation and enculturation on mental health: Does the measure matter? - CORRIGENDUM}

\author{
Alan Meca, Seth J. Schwartz, Charles R. Martinez and Heather H. McClure
}

doi:10.1017/S0954579418001165, published by Cambridge University Press, 20 October 2018

The original publication of this article (Meca et al., 2018) contained a typographical error in the article title. The article has since been corrected.

\section{Reference}

Meca, A., Schwartz, S., Martinez, C., \& McClure, H. (2018). Longitudinal effects of acculturation and enculturation on mental health: Does the measure matter? Development and Psychopathology, 30(5), 1849-1866. doi:10.1017/S0954579418001165 